\title{
Current status of and factors associated with social isolation in the elderly living in a rapidly aging housing estate community
}

\author{
Kayoko Gouda $\cdot$ Reiko Okamoto
}

Received: 5 March 2012/Accepted: 30 March 2012/Published online: 24 April 2012

(C) The Japanese Society for Hygiene 2012

\begin{abstract}
Objectives The aim of this study was to examine social isolation development among elderly persons living in a rapidly aging housing estate community in terms of the frequency of activities of daily living outside the home and social contact with neighbors and to identify associated factors.

Methods A self-administered questionnaire survey was conducted in 2007 (102 subjects) and 2010 (104 subjects) involving elderly residents living on a suburban housing estate. The data collected on the 87 subjects who responded to both surveys were analyzed. The survey investigated physical, psychological, and social factors regarded as being associated with social isolation. The subjects were divided into four social types according to the frequency of activities of daily living outside the home and social contact with neighbors. Multiple logistic regression analysis involved would-be-isolated and non-isolated groups as dependent variables and each factor as an independent variable.

Results Isolated group subjects increased from 2.3 to $7.0 \%$ during the study period, with the would-be-isolated group accounting for $33.7 \%$ of the study population in both years. Factors strongly associated with the would-beisolated group were a low subjective sense of well-being and socioeconomic status were identified in 2007 , and an
\end{abstract}

K. Gouda $(\square)$

Department of Nursing, Faculty of Health Sciences,

Kagawa Prefectural University of Health Sciences,

Mure-cho, Takamatsu City, Kagawa 761-0123, Japan

e-mail: gouda@chs.pref.kagawa.jp

R. Okamoto

Graduate School of Health Sciences, Okayama University,

Okayama 700-8558, Japan older age, low subjective sense of socioeconomic status, and no provision of emotional support in 2010 .

Conclusions The health condition and social well-being of the elderly on a rapidly aging housing estate community tended to decline, revealing that the number of isolated and would-be-isolated subjects is increasing. Taking preventive action against social isolation among the elderly population is essential, suggesting the need to combine community health promotion and social communication interventions and to develop programs aimed at providing opportunities for elderly persons to be emotional support providers.

Keywords Housing estate - Elderly - Social isolation . Prevention of social isolation - Social support

\section{Introduction}

In Japan, the development of suburban residential communities was promoted during the period of economic growth as a means to solve the problem of housing shortage, with the result that many housing estates have been built, mainly in foothill areas $[1,2]$. The current residents of such communities moved into their homes almost at the same time, when they were mostly of working-age, i.e., in their 30s and 40s. Many socially related problems have since arisen in these communities, such as simultaneous progression of an aging population within the community, a decreasing number of family members due to children leaving home or the death of a spouse, and a weakened relationship with neighbors caused by a work-oriented lifestyle, all of which raise concerns of a weakening-or disappearance - of the social structure within the entire community in the near future [3-5]. In addition, the foothill environment limits the social activities of elderly people 
and makes their lives more isolated, leading to the risk of a solitary death [6]. In answer to the recent increases in the number of solitary deaths in Japan [7], the Ministry of Health, Labour, and Welfare has established a "council to promote the creation of a community where elderly people can live safely and independently (to prevent 'dying alone')". It has also stressed the importance of creating a "community that can prevent solitary deaths" by increasing community awareness and specified the need to establish a system based on each community [8]. It is therefore important that residents of housing estates create a new bond among themselves that will result in sense of community and thereby create a society in which elderly people can enjoy their lives after retirement with peace of mind, possibly contributing to less social isolation and fewer solitary deaths. However, it is necessary to identify the process of developing social isolation in the elderly living on housing estates in order to create such a community.

Most previous studies on housing complexes have involved large-scale apartment complexes. Those studies involving housing estates have mostly focused on aspects of architecture [2] and domestic science [5], and only a few have focused on the aspect of community health $[9,10]$. However, since the standard index of social isolation and its criteria have not been integrated, various concepts of social isolation have been operationally defined in each study to identify its incidence and associated factors [11]. Within this context and based on Townsend's definition of social isolation: "the absence of social contacts with family and community" [12], we have identified forms of social isolation among elderly people living in large-scale apartment complexes in large cities or commuter towns on the outskirts of urban areas. Previous studies have identified some of the factors contributing to social isolation among the elderly as older age, male, single, lower income, depression, deterioration in physical and mental functioning, childlessness, and difficulty in obtaining individual support [13-16]. However, to date, no practical preventive measures based on these results have been reported.

The aim of the study reported here was to identify the process of developing social isolation and its associated factors by focusing on social contact among neighbors and to determine optimal forms of community structure that can prevent social isolation and maintain the quality of life (QOL) of elderly people living on a housing estate.

Definition of terms A housing estate refers to a group of single-unit family homes which were built together as a single development. Since elderly people's areas of activity are likely to become more limited to their own town or neighborhood community as they become older [17] and their daily activities also become limited to a small area, the term "community" is used to describe this small area in this study. "Social isolation among the elderly" was operationally defined as a "lack of daily activity outside the home and social interactions within the community" by adopting Townsend's objective definition [12], i.e., "the absence of social contacts with family and community", as well as the definition of housebound status, i.e., "frequency of daily activity outside the home equal to or less than once a week", which is currently used by many researchers. The criterion for measuring social isolation was considered to be "the frequency of daily activity outside the home and social interactions within the community equal to or less than three times a month" because it is considered essential that such activities be performed at least once a week in light of social and financial factors and the geographical environment of elderly subjects.

\section{Study methods}

Subjects and methods

The subjects were all elderly persons aged 65 or older who live on a "B" housing estate in a core city of Japan. A selfadministered questionnaire survey was conducted in September 2007 (the first survey) and February 2010 (the second survey) involving the same subjects. The first and second surveys involved 102 and 104 subjects, respectively.

Survey methods and items on the questionnaire

The contents on the survey questionnaire and the distribution methods were the result of several discussions with staff members of the residential community. The survey questionnaires were distributed by the staff members of the residential community after they made requests to residents to participate in the survey. The questionnaires were collected by the researchers 1 week after they had been distributed.

The survey questionnaire focused on basic attributes of the subjects and on physical, psychological, and social factors that were regarded as parameters associated with social isolation.

\section{Basic attributes}

Gender, age, number of household members, and length of residence were investigated.

\section{Physical factors}

The survey investigated the number of diseases under treatment, experience of falls over the last 1 year, and 
instrumental activities of daily living (IADL). The question on the number of diseases under treatment consisted of 15 choices, including hypertension, stroke, diabetes, heart disease, liver disease, hyperlipidemia, cancer, depression, dementia, dental caries/periodontal disease, gastrointestinal disease, eye disease, bone and joint disease, respiratory disease, and allergic disease, and the subjects were divided into a "group with $<2$ diseases" and a "group with $>3$ diseases" according to the total number of diseases they were being treated for. The IADL was measured using five subscales concerning instrumental ADLs (the ability to use public transport, buy daily necessities, prepare meals, manage finances, and fill in a pension or insurance form) of the Tokyo Metropolitan Institute of Gerontology (TMIG) Index of Competence [18]. Each item was scored either as 0 (not capable) or 1 (capable) based on the subject's ability, and the total IADL score was calculated, which ranged from 0 to 5 points, with higher scores indicating higher levels of IADL. The subjects were divided into a "lowscore group ( $0-3$ points)" and a "high-score group (4-5 points)" based on the score. Cronbach's $\alpha$ for the IADL at the first and second surveys was 0.897 and 0.927 , respectively.

\section{Psychological factors}

The subjective sense of well-being and depression were investigated. The subjective sense of well-being was rated on a 4-point scale, and subjects were divided into a "healthy group (subjects who responded as being very healthy and somewhat healthy)" and an "unhealthy group (subjects who responded as being not very healthy and unhealthy)". The 15-item Geriatric Depression Scale (GDS) [19] was used to assess depression. Each item was scored as 0 (no) or 1 (yes), and the total score was calculated after reverse scoring the appropriate items. Scores ranged from 0 to 5 points. Conventionally, scores of $0-4$ are considered to be normal, those of 5-9 indicate mild depression, and those of $\geq 10$ indicate severe depression; however, in this study, the subjects were divided into a "healthy group (no depression)" and a "depression group (mild and severe depression)". Cronbach's $\alpha$ for the GDS at the first and second survey was 0.842 and 0.773 , respectively.

\section{Social factors}

The survey investigated the frequency of activities of daily living outside the home, frequency of social contact with neighbors, status of long-term care needed, hobbies and activities, subjective socioeconomic status (hereafter referred to as household income), and social support. The frequency of activities of daily living outside the home was rated on a 5-point scale, ranging from "almost every day" to "less than once a month", and the subjects were divided into a "high-frequency group (more than once a week)" and a "low-frequency group (less than three times a month)". The frequency of social contact with neighbors was also rated on a 5-point scale, ranging from "almost every day" to "no social contact", and the subjects were divided into a "high-frequency group (more than once a week)" and a "low- frequency group (less than three times a month)". The question regarding hobbies and activities consisted of 11 items (audio-visual, music, culture, creation, sightseeing, investment gambling, gardening, sports, outdoor activities, taking care of pets, and others), and the subjects were divided into a "group with less than 2 activities" and a "group with more than 3 activities" according to the total number of activities they were engaged in. Household income was rated on a 5-point scale, and the subjects were divided into a "higher income group (higher than the average, slightly higher than the average, average)" and a "lower income group (slightly lower than the average, lower than the average)". Social support was measured using the following questions on a 2-point scale based on the scale developed by Noguchi et al. [20]: "I have someone to talk with about my concerns and complaints" (acceptance of emotional support), "I listen to concerns and complaints of other people" (provision of emotional support), "I have someone to take care of me in case of serious disease or being sick" (acceptance of instrumental support), and "I take care of someone in case of serious disease or being sick" (provision of instrumental support).

\section{Methods of analysis}

In this study we analyzed elderly persons who responded to both questionnaires in 2007 and 2010 to compare their health status and social activities associated with the progression of an aging population living in the housing estate community. Of the 101 and 102 subjects who responded to the questionnaire in 2007 and 2010, respectively, and following the exclusion of 12 subjects who died after 2007 and one person who moved out of the housing estate, the remaining 87 subjects who responded to both questionnaires were included in the study. The number of cases for each analysis varied due to missing data. In the matchedpair data, McNemar's test and the Wilcoxon signed-rank sum test were used to compare the difference in the results between the two surveys. The association between the frequency of social contacts with neighbors and other items was examined in each survey using the $\chi^{2}$ test. Based on the results of the frequency of activities of daily living outside the home and social contact, the subjects were divided into four groups: (1) "high frequency of both 
activities of daily living outside the home and social contact" (non-isolated group), (2) "low frequency of activities of daily living outside the home and high frequency of social contact" (inactive and non-isolated group), (3) "high frequency of activities of daily living outside the home and low frequency of social contact" (would-be-isolated group), and (4) "low frequency of both activities of daily living outside the home and social contact" (isolated group). Each parameter was compared using the $\chi^{2}$ test (adjusted standardized residuals were used). Since the results showed a significant correlation in most of the parameters between the would-be-isolated and non-isolated groups, the would-be-isolated group with "high frequency of activities of daily living outside the home and low frequency of social contact" was considered a characteristic of this housing estate. In order to identify characteristics of the would-be-isolated group, we compared each parameter between the would-be-isolated and non-isolated groups using the $\chi^{2}$ test. Each parameter between the non-isolated and would-be-isolated groups was compared in each survey using the $\chi^{2}$ test. Since "high frequency of activities of daily living outside the home and low frequency of social contact" (the would-be-isolated group) was considered to be a characteristic of this housing estate, the "non-isolated group" was coded as 0 and the "the would-be-isolated group" as 1; multiple logistic regression was then applied to identify risk factors associated with social isolation. A step-down procedure based on the likelihood ratio test was used to select variables (criteria $p=0.2$ ). Table 2 shows the input variables with a high significance level and those associated with social support in 2007 (including age, subjective sense of well-being, depression, experience of falls, hobbies and activities, household income, acceptance and provision of emotional support, and acceptance and provision of instrumental support) and age, subjective sense of well-being, depression, IADL, hobbies and activities, household income, acceptance and provision of emotional support, and acceptance and provision of instrumental support in 2010. The PASW Statistics 20 (SPSS, Chicago, IL) was used with a two-tailed significance level of 0.05 .

\section{Overview of "B" housing estate}

The "B" housing estate was created in the 1970s as a commuter town in a suburban foothill area of City "A" which was economically developed where branch or subsidiary firms converged. As of 1 October 2005 a total of 420 people resided in this housing estate, divided over 164 households. Elderly people accounted for $24.9 \%$ of the total number of residents, and $72 \%$ of households consisted only of elderly persons. Twenty children lived in this housing estate. Approximately $80 \%$ of the residents were from outside the prefecture, so they had no strong regional bond or affinal relations with neighbors and did not strive to socially interact with different generations through traditional events or community activities. In addition, since there is no shopping center or public transport around this area, many of the elderly residents, once becoming incapable of driving a car safely, experienced anxiety in their daily lives. In 2005, a collaboration among the community, a university, and public administration resulted in the formation of a Community-Based Participatory Research (CBPR) project [21] aimed at creating a community with no solitary deaths. A community association has since been established to maintain regular contact with the elderly, provide opportunities for interaction, and foster social interactions among different generations.

Ethical considerations

This study was conducted with the approval of the ethics committee of Kagawa Prefectural University of Health Sciences (Approval No. 3). A letter informing all potential participants of the ethical issues, including study methods, was enclosed with the survey, and the return of the completed survey questionnaire was considered to indicate informed consent. Data were statistically processed and stored in a locked room.

\section{Results}

Characteristics of changes in the subjects

Responses were obtained from 101 of the 102 subjects (response rate $99.1 \%$ ) in the first (2007) survey and from 102 of the 104 subjects (response rate $98.1 \%$ ) in the second (2010) survey. The analysis was conducted using data obtained from the 87 who responded to both questionnaires (2007 and 2010). Table 1 shows the distribution of the subjects' basic attributes and social isolation-related parameters (hereafter referred to as parameters). Male and female subjects accounted for 43.0 and $57.0 \%$ of the study population, respectively. The mean age of the respondents was 74.2 years in 2007 , rising to 76.7 after 2.5 years (2010). The percentage of old-old persons increased from 44.2 to $61.7 \%$. The mean length of residence was 25 years. The percentage of elderly persons living alone increased by $4.8 \%$ between 2007 and 2010, reaching $20 \%$ in 2010. Although $83.9 \%$ of respondents said they lived with family members, $71.2 \%$ of these lived only with their (elderly) spouse. In 2010, the percentage of elderly persons living with their family members decreased by $6.4 \%$. In terms of physical health, between 2007 and 2010 the subjects who experienced falls increased from 18.4 to $28.7 \%$, 
those who had lower IADL scores increased from 11.8 to $17.6 \%$, and those who had been certified in need of longterm care also increased from 8.3 to $19.0 \%$, showing a deterioration in health status. Regarding psychological health, subjects who had a lower sense of well-being and depressive symptoms accounted for 34 and $23.5 \%$, respectively, of the respondents in both 2007 and 2010, with no significant change observed between surveys. In terms of social state, $17.1 \%$ of respondents considered that they had a lower household income in both years. In 2007, approximately $70 \%$ of respondents enjoyed more than three activities; however this percentage had slightly decreased in 2010. The subjects who went out less than three times a month increased from 9.3 (2007) to $15.1 \%$ (2010), and those who had less social contact with neighbors also increased from 36.0 to $40.7 \%$ during this time period. With respect to the four groups based on the frequency of activities of daily living outside the home and social contact, 57.0 and $51.2 \%$ of the respondents fell into the "non-isolated group" in 2007 and 2010, respectively, a decrease of $5.8 \%$ during the study period. Conversely, the "isolated group" with a low frequency of both frequency of activities of daily living outside the home and social contact accounted for 2.3 and $7.0 \%$ of the respondents in 2007 and 2010, respectively, which is a slight increase. The "inactive and non-isolated group" with a low frequency of activities of daily living outside the home and a high frequency of social contact accounted for 7.0 and $8.1 \%$ of the respondents in 2007 and 2010, respectively, showing little change. The would-be-isolated group with a high frequency of activities of daily living outside the home and a low frequency of social contact accounted for $33.7 \%$ of the respondents in both 2007 and 2010. In terms of social support, $70-80 \%$ of the subjects accepted and provided both emotional and instrumental support, but no longitudinal change was observed. However, the number of subjects who accepted support slightly increased during the study period, while the number of those who provided it tended to decrease.

The association between the frequency of activities of daily living outside the home and social contact, and social isolation-related parameters

To identify the characteristics of the "would-be-isolated group (high frequency of activities of daily living outside the home and low frequency of social contact)", we compared the parameters between the "would-be-isolated group" and the "non-isolated group (high frequency of both activities of daily living outside the home and social contact)". The results of this comparison are presented in Table 2. Although the total subject cohort in this study comprised 87 individuals, only 78 individuals in 2007 and
73 individuals in 2010 were compared from the "would-beisolated" and "non-isolated" groups of Table 1. Due to missing data, each item does not necessarily add up to the total number of subjects. In 2007, the "would-be-isolated group" was associated with subjective well-being, depression, experience of falls, fewer hobbies and activities, a lower household income, and absence of instrumental support. In 2010, in addition to the above factors, but with the exception of household income, aged $\geq 75$ years, status of long-term care need, lower levels of IADL, absence of acceptance and provision of emotional support were also associated with the "would-be-isolated group". No association was observed with gender, household composition, and the number of diseases. Of the 29 subjects who were categorized into the "would-be-isolated group" in 2007, $14(48.3 \%)$ had remained in the same group in 2010 , three $(10.3 \%)$ had shifted to the "isolated group", and two (6.9\%) had shifted to the "inactive and non-isolated group"; in contrast, ten subjects had successfully shifted to the "non-isolated group".

Multiple logistic regression analysis of factors associated with the "isolated group"

Tables 3 and 4 show the results of multiple logistic regression analysis of the parameters that were found to be significant between the "would-be-isolated" and "nonisolated" groups for both 2007 and 2010. As factors associated with the frequency of activities of daily living outside the home and social contact with neighbors, we identified the subjective sense of well-being and household income in 2007 (model $\chi^{2}$ test, $p<0.001$ ). The odds ratio of the subjective sense of well-being and household income were 4.47 [95 \% confidence interval (CI) 1.32-15.19] and 9.33 (95\% CI 1.66-52.39), respectively. The results show that the subjective sense of well-being and household income significantly influenced the frequency of activities of daily living outside the home and social contact with neighbors. Specifically, the subjects who have a lower subjective sense of well-being and those with a lower household income were at a 4.47 -fold and 9.33-fold greater risk becoming socially isolated, respectively.

Age, household income, and provision of emotional support were identified in 2010 as factors associated with the frequency of activities of daily living outside the home and social contact with neighbors (model $\chi^{2}$ test, $p<0.001)$. The odds ratio of age, household income, and provision of emotional support were 22.92 (95\% CI 1.68-312.88), 9.56 (95\% CI 1.02-89.83), and 10.19 (95\% CI 1.41-73.68), respectively. Thus, the results showed that age, household income, and provision of emotional support significantly influenced the frequency of activities of daily living outside the home and social contact with neighbors. 
Table 1 Distribution of basic attributes and parameters associated with social isolation in 2007 and 2010

\begin{tabular}{|c|c|c|c|c|c|c|}
\hline \multirow[t]{2}{*}{ Basic attributes/social isolation-related parameters } & \multirow[t]{2}{*}{$n$} & \multicolumn{2}{|c|}{2007} & \multicolumn{2}{|c|}{2010} & \multirow[t]{2}{*}{$p$ value $^{\mathrm{a}}$} \\
\hline & & $n$ & $\%$ & $n$ & $\%$ & \\
\hline \multicolumn{7}{|l|}{ Gender } \\
\hline Male & 87 & 38 & 43.0 & 38 & 43.0 & \\
\hline Female & & 49 & 57.0 & 49 & 57.0 & \\
\hline Age & & & & & & 0.01 \\
\hline Mean age & 86 & \multicolumn{2}{|c|}{$74.2 \pm 6.4^{\mathrm{b}}$} & \multicolumn{2}{|c|}{$76.7 \pm 6.4^{\mathrm{b}}$} & \\
\hline$\geq 75$ years & 86 & 38 & 44.2 & 53 & 61.7 & \\
\hline $65-74$ & & 48 & 55.8 & 33 & 38.4 & \\
\hline Household members & & & & & & 0.19 \\
\hline 1 & 86 & 14 & 16.1 & 18 & 20.9 & \\
\hline 2 & & 52 & 59.8 & 44 & 51.2 & \\
\hline$\geq 3$ & & 21 & 24.1 & 24 & 27.9 & \\
\hline Length of residence & 87 & \multicolumn{2}{|c|}{$25.2 \pm 7.4^{\mathrm{b}}$} & \multicolumn{2}{|c|}{$27.2 \pm 7.4^{\mathrm{b}}$} & 0.01 \\
\hline \multicolumn{6}{|l|}{ Subjective sense of well-being } & 1.00 \\
\hline Low & 87 & 30 & 34.5 & 29 & 33.3 & \\
\hline High & & 57 & 65.5 & 58 & 66.7 & \\
\hline \multicolumn{6}{|l|}{ Depression } & 1.00 \\
\hline Present & 68 & 16 & 23.5 & 16 & 23.5 & \\
\hline Absent & & 52 & 76.5 & 52 & 76.5 & \\
\hline \multicolumn{6}{|l|}{ Number of diseases under treatment } & 0.50 \\
\hline Less than 2 diseases & 87 & 21 & 24.1 & 25 & 28.7 & \\
\hline More than 3 diseases & & 66 & 75.9 & 62 & 71.3 & \\
\hline \multicolumn{6}{|l|}{ Experience of falls } & 0.08 \\
\hline Present & 87 & 16 & 18.4 & 25 & 28.7 & \\
\hline Absent & & 71 & 81.6 & 62 & 71.3 & \\
\hline \multicolumn{6}{|l|}{ IADL } & 0.01 \\
\hline Low & 85 & 10 & 11.8 & 15 & 17.6 & \\
\hline High & & 75 & 88.2 & 70 & 82.4 & \\
\hline \multicolumn{6}{|l|}{ Number of hobbies and activities } & 0.54 \\
\hline Less than 2 activities & 86 & 23 & 26.7 & 27 & 31.4 & \\
\hline More than 3 activities & & 63 & 73.3 & 59 & 68.6 & \\
\hline \multicolumn{6}{|l|}{ Household income } & 1.00 \\
\hline Low & 82 & 14 & 17.1 & 14 & 17.1 & \\
\hline High & & 68 & 82.9 & 68 & 82.9 & \\
\hline \multicolumn{6}{|l|}{ Frequency of daily activity outside the home } & 0.33 \\
\hline Low & 86 & 8 & 9.3 & 13 & 15.1 & \\
\hline High & & 78 & 90.7 & 63 & 75.0 & \\
\hline \multicolumn{6}{|l|}{ Frequency of social contact with neighbors } & 0.59 \\
\hline Low & 84 & 31 & 36.0 & 35 & 40.7 & \\
\hline High & & 55 & 64.0 & 51 & 59.3 & \\
\hline \multicolumn{7}{|l|}{ Types of social isolation } \\
\hline Non-isolation group & 86 & 49 & 57.0 & 44 & 51.2 & 0.57 \\
\hline Inactive and non-isolated group & & 6 & 7.0 & 7 & 8.1 & \\
\hline Would-be-isolated group & & 29 & 33.7 & 29 & 33.7 & \\
\hline Isolated group & & 2 & 2.3 & 6 & 7.0 & \\
\hline Status of long-term care need & & & & & & 0.01 \\
\hline Required & 84 & 7 & 8.3 & 16 & 19.0 & \\
\hline Not required & & 77 & 91.7 & 68 & 81.0 & \\
\hline
\end{tabular}


Table 1 continued

\begin{tabular}{|c|c|c|c|c|c|c|}
\hline \multirow[t]{2}{*}{ Basic attributes/social isolation-related parameters } & \multirow[t]{2}{*}{$n$} & \multicolumn{2}{|c|}{2007} & \multicolumn{2}{|c|}{2010} & \multirow[t]{2}{*}{$p$ value $^{\mathrm{a}}$} \\
\hline & & $n$ & $\%$ & $n$ & $\%$ & \\
\hline Acceptance of emotional support & & & & & & 0.26 \\
\hline Absent & 86 & 18 & 20.9 & 12 & 14.0 & \\
\hline Present & & 68 & 79.1 & 74 & 86.0 & \\
\hline Provision of emotional support & & & & & & 1.00 \\
\hline Absent & 85 & 22 & 25.9 & 23 & 27.1 & \\
\hline Present & & 63 & 74.1 & 62 & 72.9 & \\
\hline Acceptance of instrumental support & & & & & & 1.00 \\
\hline Absent & 86 & 12 & 14.0 & 11 & 12.8 & \\
\hline Present & & 74 & 86.0 & 75 & 87.2 & \\
\hline Provision of instrumental support & & & & & & 1.00 \\
\hline Absent & 78 & 9 & 10.8 & 10 & 12.0 & \\
\hline Present & & 74 & 89.2 & 73 & 88.0 & \\
\hline
\end{tabular}

IADL, Instrumental activities of daily living

a McNemar's test, Wilcoxon signed-rank sum test

b Mean \pm standard deviation (SD)

Specifically, the elderly subjects aged $\geq 75$ years, those with a lower household income, and those who provide less support to others were at a 22.92-, 9.56-, and 10.19-fold greater risk of becoming socially isolated, respectively.

\section{Discussion}

Longitudinal changes in characteristics of elderly persons living on a housing estate and the incidence of social isolation

The aim of this study was to analyze the state of social isolation among elderly persons living on a housing estate that had been developed during the period of rapid economic growth in Japan, using the results of surveys involving these elderly individuals in 2007 and 2010. Three years after the research had been initiated, the number of old-old persons exceeded that of young-old persons living on the housing estate, and many residents showed a progression towards a reduced IADL, increased need for longterm care, increased number of falls and diseases, and reduced frequency of engagement in hobbies, daily activities outside the home, and social contact with neighbors. These changes indicated increasing health and social wellbeing problems among the elderly persons together with population aging, as well as a gradual weakening of the social structure of the housing estate. It can be assumed that the overall result is a narrowing of their daily activities. In fact, the elderly subjects in the isolated group with a "low frequency of both activities of daily living outside the home and social contact" increased from $2.3 \%$ in 2007 to
$7.0 \%$ in 2010. Furthermore, in both years, $33.7 \%$ of the subjects were categorized into the would-be-isolated group with a "high frequency of activities of daily living outside the home and low frequency of social contact". This group could become easily isolated from the community due to the absence of someone they can rely on in case of illness and accounts for approximately $40 \%$ of the study population when subjects who have less social contact with neighbors are included. Since this classification of social isolation was originally developed for this study, our results cannot be directly compared to those of other studies; however, our results do show a higher incidence of social isolation compared to $1.9 \%$ of subjects with a "low frequency of both activities of daily living outside the home and social contact" and $20.2 \%$ with a "high frequency of activities of daily living outside the home and low frequency of social contact" that were reported by Hirai et al. [22] who employed almost the same criteria. The characteristics observed in the would-be-isolated group, which included those more actively involved in maintaining relationships outside the community rather than in creating them inside of it, especially suggest that there are many people who continue to maintain "selective relationships" [23] which they have sustained throughout their life, thereby actively selecting a "de-community" lifestyle [3]. However, considering the study of Yamazaki et al. [24] who reported that the daily mobility of elderly persons becomes less with age because they only go out for buying groceries or visiting hospitals, the frequency of social contact outside the community of the would-beisolated group does not seem to be so high, suggesting poor interpersonal relationships both inside and outside of the 
Table 2 Comparison between the would-be-isolated and non-isolated groups in terms of parameters associated with social isolation

\begin{tabular}{|c|c|c|c|c|c|c|c|c|c|c|c|c|}
\hline \multirow{3}{*}{$\begin{array}{l}\text { Basic attributes/social } \\
\text { isolation-related parameters }\end{array}$} & \multirow[t]{3}{*}{$n$} & \multicolumn{4}{|c|}{2007} & \multirow[t]{3}{*}{$p$ value } & \multirow[t]{3}{*}{$n$} & \multicolumn{4}{|c|}{2010} & \multirow[t]{3}{*}{$p$ value } \\
\hline & & \multicolumn{2}{|c|}{$\begin{array}{l}\text { Would-be-isolated } \\
\text { group }\end{array}$} & \multicolumn{2}{|c|}{$\begin{array}{l}\text { Non-isolated } \\
\text { group }\end{array}$} & & & \multicolumn{2}{|c|}{$\begin{array}{l}\text { Would-be-isolated } \\
\text { group }\end{array}$} & \multicolumn{2}{|c|}{$\begin{array}{l}\text { Non-isolated } \\
\text { group }\end{array}$} & \\
\hline & & $n$ & $\%$ & $n$ & $\%$ & & & $n$ & $\%$ & $n$ & $\%$ & \\
\hline Gender & & & & & & 1.00 & & & & & & 0.46 \\
\hline Male & 35 & 13 & 37.1 & 22 & 62.9 & & 29 & 10 & 34.5 & 19 & 65.5 & \\
\hline Female & 43 & 16 & 37.2 & 27 & 62.8 & & 44 & 19 & 43.2 & 25 & 56.8 & \\
\hline Age & & & & & & 0.77 & & & & & & 0.05 \\
\hline$\geq 75$ years & 36 & 14 & 38.9 & 22 & 61.1 & & 48 & 23 & 47.9 & 25 & 52.1 & \\
\hline $65-74$ & 42 & 15 & 35.7 & 27 & 64.3 & & 25 & 6 & 24.0 & 19 & 76.0 & \\
\hline Household members & & & & & & 0.98 & & & & & & 0.29 \\
\hline 1 & 13 & 5 & 38.5 & 8 & 61.5 & & 18 & 9 & 50.0 & 9 & 50.0 & \\
\hline$\geq 2$ & 63 & 24 & 38.1 & 39 & 61.9 & & 53 & 19 & 35.8 & 34 & 64.2 & \\
\hline Subjective sense of well-being & & & & & & 0.01 & & & & & & 0.01 \\
\hline Low & 29 & 18 & 62.1 & 11 & 37.9 & & 22 & 15 & 68.2 & 7 & 31.8 & \\
\hline High & 49 & 11 & 22.4 & 38 & 77.6 & & 51 & 14 & 27.5 & 37 & 72.5 & \\
\hline Depression & & & & & & 0.01 & & & & & & 0.03 \\
\hline Present & 14 & 10 & 71.4 & 4 & 28.6 & & 16 & 10 & 62.5 & 6 & 37.5 & \\
\hline Absent & 46 & 14 & 30.4 & 32 & 69.6 & & 42 & 13 & 31.0 & 29 & 69.0 & \\
\hline Number of diseases under treatment & & & & & & 0.86 & & & & & & 0.89 \\
\hline Less than 2 diseases & 18 & 7 & 38.9 & 11 & 61.1 & & 22 & 9 & 40.9 & 13 & 59.1 & \\
\hline More than 3 diseases & 60 & 22 & 36.7 & 38 & 63.3 & & 51 & 20 & 39.2 & 31 & 60.8 & \\
\hline Experience of falls & & & & & & 0.02 & & & & & & 0.01 \\
\hline Present & 14 & 9 & 64.3 & 5 & 35.7 & & 22 & 14 & 63.6 & 8 & 36.4 & \\
\hline Absent & 64 & 20 & 31.3 & 44 & 68.8 & & 51 & 15 & 29.4 & 36 & 70.6 & \\
\hline IADL & & & & & & 0.17 & & & & & & 0.03 \\
\hline Low & 10 & 6 & 60.0 & 4 & 40.0 & & 14 & 9 & 14.3 & 5 & 35.7 & \\
\hline High & 66 & 23 & 34.8 & 43 & 65.2 & & 57 & 19 & 23.3 & 38 & 66.7 & \\
\hline Number of hobbies and activities & & & & & & 0.05 & & & & & & 0.03 \\
\hline Less than 2 activities & 22 & 12 & 54.5 & 10 & 45.5 & & 23 & 13 & 56.5 & 10 & 43.5 & \\
\hline More than 3 activities & 56 & 17 & 30.4 & 39 & 69.6 & & 50 & 16 & 32.0 & 34 & 68.0 & \\
\hline Household income & & & & & & 0.01 & & & & & & 0.07 \\
\hline Low & 11 & 9 & 81.8 & 2 & 18.2 & & 13 & 8 & 61.5 & 5 & 38.5 & \\
\hline High & 62 & 20 & 32.3 & 42 & 67.7 & & 56 & 19 & 33.9 & 37 & 66.1 & \\
\hline Status of long-term care need & & & & & & 0.41 & & & & & & 0.02 \\
\hline Required & 7 & 4 & 57.1 & 3 & 42.9 & & 15 & 10 & 66.7 & 5 & 33.3 & \\
\hline Not required & 68 & 24 & 35.3 & 44 & 64.7 & & 56 & 18 & 32.1 & 38 & 67.9 & \\
\hline Acceptance of emotional support & & & & & & 0.78 & & & & & & 0.01 \\
\hline Absent & 17 & 7 & 41.2 & 10 & 58.8 & & 11 & 9 & 81.8 & 2 & 18.2 & \\
\hline Present & 61 & 22 & 36.1 & 39 & 63.9 & & 61 & 19 & 31.1 & 42 & 68.9 & \\
\hline Provision of emotional support & & & & & & 0.05 & & & & & & 0.01 \\
\hline Absent & 22 & 12 & 54.5 & 10 & 45.5 & & 19 & 14 & 73.7 & 5 & 26.3 & \\
\hline Present & 55 & 17 & 30.9 & 38 & 69.1 & & 52 & 13 & 25.0 & 39 & 75.0 & \\
\hline Acceptance of instrumental support & & & & & & 0.04 & & & & & & 0.04 \\
\hline Absent & 10 & 7 & 70 & 3 & 30.0 & & 10 & 7 & 70.0 & 3 & 30.0 & \\
\hline Present & 67 & 22 & 32.8 & 45 & 67.2 & & 62 & 21 & 33.9 & 41 & 66.1 & \\
\hline Provision of instrumental support & & & & & & 0.08 & & & & & & 0.29 \\
\hline Absent & 9 & 6 & 66.7 & 3 & 33.3 & & 9 & 5 & 55.6 & 4 & 44.4 & \\
\hline Present & 66 & 23 & 34.8 & 43 & 65.2 & & 61 & 22 & 36.1 & 39 & 63.9 & \\
\hline
\end{tabular}


Table 3 Multiple logistic regression analysis of factors associated with the "would-be-isolated group" (2007)

\begin{tabular}{llccc}
\hline Social isolation-related parameters & $p$ value & Odds ratio & \multicolumn{2}{c}{$95 \%$ Confidence interval } \\
\cline { 3 - 5 } & & & Lower & Upper \\
\hline Low subjective sense of well-being (reference: high) & 0.016 & 4.47 & 1.32 & 15.19 \\
Low household income (reference: high) & 0.011 & 9.33 & 1.66 & 52.39 \\
\hline
\end{tabular}

Model $\chi^{2}$ test, $p<0.001$; Hosmer-Lemeshow test, $p=0.625$; accuracy rate, $71.2 \%$

Table 4 Multiple logistic regression analysis of factors associated with the "would-be-isolated group" (2010)

\begin{tabular}{llllc}
\hline Social isolation-related parameters & $p$ value & Odds ratio & \multicolumn{2}{c}{$95 \%$ Confidence interval } \\
\cline { 3 - 5 } & & & Lower & Upper \\
\hline 75 years (Reference; 65-74 years) & 0.019 & 22.92 & 1.68 & 312.88 \\
Low household income (reference: high) & 0.048 & 9.56 & 1.02 & 89.83 \\
Absence of provision of emotional support (reference: present) & 0.021 & 10.19 & 1.41 & 73.68 \\
\hline
\end{tabular}

Model $\chi^{2}$ test, $p<0.001$; Hosmer-Lemeshow test, $p=0.370$; accuracy rate, $83.3 \%$

community. Furthermore, considering a marked decline in the frequency of activities of daily living outside the home after the age of 80 years [25, 26], it is certain that many (if not all) of the would-be-isolated group shift to the isolated group. Thus, preventive measures against shifting to the isolated group are urgently needed.

Although it has been reported to be difficult to obtain data directly from isolated elderly persons for the purposes of investigating their actual status [13], this study achieved a nearly $100 \%$ response rate-although the number of subjects was relatively small-indicating that this study obtained a representative picture of the elderly persons living on the housing estate in terms of social isolation. Among the four types of social isolation described here, the subjects of the would-be-isolated group with a "high frequency of activities of daily living outside the home and a low frequency of social contact" objectively represented the social status of "attenuated inter-community relationships" which has been noted among the residents based on the frequency of activities of daily living outside the home and social contact.

Factors associated with social isolation

To identify the characteristics of the would-be-isolated group, which can be considered to be one of the main groups of this housing estate, we compared each parameter of this group with that of the non-isolated group. We found that household composition [27] and male gender [13], which are conventionally considered to be risk factors for developing social isolation, were not associated with social isolation in both 2007 and 2010. Females are generally reported to have a broader network than males [28-30], but this was not observed in our study, suggesting that the female subjects on this housing estate, who are mostly housewives, did not strive to socially interact with their neighbors. Furthermore, we observed no difference by household composition, suggesting that the size of the local network of females may be related. Given the up-coming retirement of the baby-boom generation, social projects have focused on promoting the community participation of male individuals; however, in such a community as the one studied here, with no interaction, the first step would appear to be to encourage the formation of links irrespective of gender and thereby utilize women's potential ability to create relationships [28-30] and to examine a system to build a closer bond among the residents using women's networks as the basis.

In comparison to the non-isolated group, more subjects in the would-be-isolated group experienced falls; they also showed a reduced IADL, depression, lower subjective sense of well-being, reduced number of hobbies and activities, and a lower household income; these factors can all be considered to affect independent living of the elderly and reveal that social isolation among our study cohort was associated with physical, psychological, and social factors. In terms of the acceptance and provision of social support, no acceptance of instrumental support was associated with social isolation in 2007; in addition, in 2010, no acceptance and provision of emotional support was associated with social isolation. Of these factors, reduced physical and psychological functioning, lower household income, and no acceptance of social support resemble the characteristics of the socially isolated elderly $[13,15]$; however, a reduced number of hobbies and activities and no provision of emotional support were identified as characteristics of the would-be-isolated group.

The results of multiple logistic regression analysis showed that the factors associated with the would-beisolated group were a subjective sense of well-being and 
household income in 2007, and age, household income, and provision of emotional support in 2010.

With respect to older age and lower household income, our results are consistent with those of previous studies [14, 16]; however, our associations with the subjective sense of well-being and provision of emotional support are novel findings of our study. Since the subjective sense of wellbeing, which is a comprehensive health parameter [31], and socioeconomic factors related to physical and psychological health and living status [32] were associated with the would-be-isolated group, we consider that multiple factors are intricately linked to social isolation.

In terms of accepting and providing social support, it has been reported that a more favorable health status can be achieved when the subjects have an appropriate balance of both accepting and providing support [33]; however, our study revealed that the would-be-isolated group was more closely associated with the provision of emotional help than with the acceptance of it. There was no difference in the two groups regarding instrumental support, possibly because this support involves physical assistance or nursing care which is closely associated with the deterioration in physical and psychological functioning associated with aging. In contrast, the provision of emotional support by elderly persons involves the emotions and feelings of the receivers of this support who are being provided with comfort, encouragement, and someone to listen to their worries; this provision of support has been reported to increase the self-esteem and offer peace of mind to elderly support providers [34]. Although this support has been reported to decrease with aging [33, 35], the provision of support can positively affect the health status and increase the life satisfaction of elderly persons by, for example, slowing down the deterioration of physical and psychological functioning and preventing early death [28, 36, 37]. Thus, our results suggest the importance of creating a community where elderly persons not only accept but also provide support to prevent social isolation.

Creating a community aimed at preventing social isolation among the elderly

Actions aimed at preventing the social isolation of elderly persons living on a housing estate were explored in this study using factors that were identified to be associated with the would-be-isolated group. Preventive actions against social isolation were conducted in 78 autonomous communities in 2007, which mainly involved the creation of a community to prevent solitary deaths and social isolation, including investigating the actual status, observing and confirming the health status, providing opportunities for interaction, and establishing a social network [38]. Given the fact that reduced physical and psychological functioning is a factor causing social isolation in elderly persons [13], it is considered essential to develop a program which incorporates exercise intervention with a communication-building approach that can encourage mutual interactions among residents. For example, because many subjects in the would-be-isolated group experienced falls, creating a walking club can be an optimal preventive measure against social isolation in terms of both improving lower-limb muscles and making friends by taking advantage of the foothill environment. Hoshi et al. [39] reported that people who enjoy outdoor activities, including hiking, have a higher subjective sense of well-being, thereby indicating the importance of adopting outdoor health interventions as a preventive measure.

The results of this study also indicate the need to develop a program which encourages elderly persons not only to accept the need for support but also to become actively involved in providing support. Fujiwara et al. [40] developed a program which incorporated intellectual volunteer activities of elderly subjects and reported an improved subjective sense of well-being among the elderly subjects and an enhancement of social support networks. However, since their study was conducted at an educational facility involving young-old elderly subjects with higher levels of social activity, it is difficult to directly apply their results to those of our subjects who were mainly old-old elderly persons. Programs should be developed in the future that provide an opportunity for old-old persons to become an emotional support provider, as this provides something to live for and facilitates self-esteem by giving elderly persons a social role. Essentially, relationships among residents are horizontal; therefore, it is important to create a program which can maintain the homogeneity of the residents and not to hurt their pride. As Kobayashi [41] suggested, the acceptance of support which one cannot pay back contributes to a decrease in self-esteem and additionally carries the risk of developing social isolation from the community.

Our study has a number of limitations and strengths. This study was conducted to identify the actual status of social isolation by defining such isolation on the basis of the frequency of activities of daily living outside the home and social contact, with the aim of creating a community in which elderly people can live safely by socially interacting with neighbors. Data were obtained on individuals who responded to both questionnaires in 2007 and 2010, following the exclusion of those individuals who died after 2007 and one individual who moved out of the housing estate. Although these subjects were not arbitrarily chosen, healthy subject bias should be considered because those who died after 2007 were excluded. However, we obtained high response rates from the two surveys conducted at different time periods which, to some extent, contributed to 
the identification of factors associated with social isolation in the elderly living in the housing estate community, although causal relationships cannot be inferred from cross-sectional studies. Further studies should be conducted to collect evidence based on the extracted factors using intervention research. In our study, the purposes of going out and making social contact with neighbors have yet to be identified and require further analysis of qualitative data collected separately. In addition, although this study did not include family interaction for analytical purposes, this aspect should be analyzed in terms of preventing solitary deaths. Lastly, the findings were limited to a small group of elderly persons living on a housing estate in a suburban area, suggesting that the survey results obtained may be specific to this region. The small sample size involved in this study should also be noted. Further study should be conducted involving samples from different locations to investigate social isolation, accumulate findings on the actual status of regional interaction among residents, and enhance the possibility for generalizing the results.

Acknowledgments We thank the residents of the "B housing estate and all of the people involved in community- and home-based mental health nursing of the Kagawa Prefectural University of Health Sciences for their cooperation in this study. We are also grateful to Prof. Nobuko Takashima for her valuable advice and support throughout the writing process. This study was supported by a 2008-2010 grantin-aid for scientific research (C) from the Ministry of Education, Culture, Sports, Science, and Technology ["Constructing a model for forming community associations on a housing estate with aging residents, and analyzing the roles of residents and public health nurses in the process" (corresponding author: Kayoko Gouda)].

Conflict of interest None.

\section{References}

1. Honma Y. Verification of post-war housing development. Tokyo: Shinzansha Publisher; 2004. p. 4-48.

2. Nakaya M, Yamada K, Sawai M, Yamada H. The actual conditions of suburban detached area developed in the high growth period: a study on the conditions and residential consciousness of suburban housing in Kanazawa City part 1 (in Japanese). J Arch Build Sci. 2004;47:328-31.

3. Hayami S. Local transformation of the suburbs city communityaging and meaning of "the suburbs" (in Japanese). Ann Jpn Assoc Urban Sociol. 2001;9:55-69.

4. Kuroda M. Aging society and community development. In: Matsuda Y, Nishimura M, editors. Introduction to regional sciences. Sekaishisosha: Kyoto; 1999. p. 116-8.

5. Imai N, Ito R. The problem of the trend of parent and child's resident status, and living environment of a "Remote Suburban Residential Section" in Haibara-cho, Nara (in Japanese). J Home Econ Jpn. 2006;57:761-74.

6. Gouda K, Takashima N, Tsuji Y, Kunikata H, Nakazoe K. Response of "housing complex summit" held aiming at ripple effect of make with community in the housing complex (in Japanese). J Shikoku Public Health Soc. 2010;55:133-7.

7. Fukushima S, Sakai K. A study on the current status of solitary living among the elderly in a large-scale apartment complex in a metropolitan area and livelihood support(in Japanese). J Health Welf Stat. 2010;57:1-8.

8. Health Planning Division of the Health and Welfare Bureau for the Elderly, Ministry of Health, Labour, and Welfare. A council to promote the creation of a community where elderly people can live safely and independently (to prevent "dying alone"). Tokyo: 2008. p. 1-19.

9. Gouda K, Kunikata H, Takashima N, Tsuji Y, Nakazoe K. Correlations between the tooth condition of elderly people living in housing-development residences and their positive self-esteem, depression, and state regarding going out (in Japanese). Nihon Kango Kenkyu Gakkai Zasshi. 2010;33:51-7.

10. Omori J. Correlation between interactions of younger elderly women with close non-family friends and neighbors and healthrelated QOL (in Japanese). Jpn J Public Health. 2007;54:605-13.

11. Saito M. The meaning and problems of the study concerning social isolation of the elderly as social welfare research (in Japanese). J Soc Welf Nihon Fukushi Univ. 2009;121:29-41.

12. Townsend P. Isolation, loneliness, and the hold on life. In: Townsend P, editor. The family life of old people: an inquiry in East London. Harmondsworth: Penguin Books; 1963. p. 188-205.

13. Saito M, Fujiwara Y, Kobayashi E, Fukaya T, Nishi M, Shinkai S. Prevalence and characteristics of social isolation in the elderly in a dormitory suburb according to household composition (in Japanese). Jpn J Public Health. 2010;57:785-95.

14. Saito M, Shimizu Y, Yamaguchi M, Takei S. Prevalence and characteristics of the socially isolated elderly in a large urban area (in Japanese). Jpn Soc Study Soc Welf. 2009;50:110-22.

15. Kobayashi E, Fujiwara Y, Fukaya T, Nishi M, Saito M, Shinkai S. Social support availability and psychological well-being among the socially isolated elderly. Differences by living arrangement and gender (in Japanese). Jpn J Public Health. 2011;58:446-56.

16. Hawthorone G. Perceived social isolation in a community sample: its prevalence and correlates with aspects of people' lives. Soc Psychiatry Psychiatr Epidemiol. 2008;43:140-50.

17. Ayakami Town. Ayakami Town Community Welfare Project "Ayakami Health Promotion 21, Shifuku-no-Fukushi (Wonderful and accessible welfare service)". Kagawa: Ayakami-cho; 2008. p. $42-3$.

18. Koyano W, Shibata H, Nakazato K, Haga H, Suyama Y. Evaluation of physical functioning among community-dwelling elderly: development of a TMIG-Index of Competence (in Japanese). Jpn J Public Health. 1987;34:109-14.

19. Yesavage JA, Brink TL, Rose TL, Lum O, Huang VS, et al. Development and validation of a geriatric depression screening scale: a preliminary report. J Psychiatr Res. 1983;17:37-9.

20. Noguchi Y. Social support among the elderly: concept and measurement (in Japanese). Soc Gerontol. 1991;34:37-48.

21. Kiyomi A. Community-based participatory research for community health in Japan-theory and practice. Tokyo: Ishiyaku Publishers, INC; 2010. p. 2-36.

22. Hirai H, Kondo K, Ichida Y, Suemori K. The elderly in Japan-a large-scale social epidemiological survey for care prevention (6): "houseboundness" among the elderly (in Japanese). J Public Health Pract. 2005;69:485-9.

23. Kaneko I. Social networks of old people in urban communities. Jpn Sociol Rev. 1987;38:336-50.

24. Yamazaki S, Hashimoto M, Imuta $H$, Shigeta $M$, Haga $H$, Yasumura S. Frequency of homebound elderly people living in an urban community and factors related to a homebound state (in Japanese). Jpn J Gerontol. 2008;30:58-68. 
25. Shinkai S, Fujita K, Fujiwara Y, Kumagai S, Amano H, Yoshida $\mathrm{H}$. Predictors for the onset of different types of homeboundness among community-living older adults: two-year prospective study (in Japanese). Jpn J Public Health. 2005;52:874-85.

26. Ishihara T, Mizuno K, Furuzawa H, Gokan Y. A study of support systems for elderly people who live in mountainous are housebound and who have limited opportunity for out-of-house travel (in Japanese). J Jpn Acad Commun Health Nurs. 2004;7:62-7.

27. Victor C, Scambaler S, Bond J, Bowling A. Being alone in latter life: loneliness, social isolation and living alone. Rev Clin Gerontol. 2000;10:407-17.

28. Kishi R, Horikawa N. Role of the social support network which influences age of death and physical function of elderly people: study of trends in and outside of Japan and future problems (in Japanese). Jpn J Public Health. 2004;51:79-93.

29. Murata C, Saito Y, Kondo K, Hirai H. Social support and depression among community living older people AGES Project (in Japanese). Jpn J Gerontol. 2011;33:15-22.

30. Kobayashi E, Sugihara Y, Fukaya T, Akiyama H, Liang J. Effects of marital status and geographic distance from children upon network structure and functions of friends and neighbors among the Japanese elderly (in Japanese). Jpn J Gerontol. 2005;26: 438-50.

31. Sugisawa H, Sugisawa A. Development of research on self-rated health in the United States (in Japanese). Jpn J Public Health. 1995;42:366-78.

32. Kondo K, Hirai H, Ichida Y, Matsuda R, Saito Y, Endo H, et al. The elderly in Japan-a large-scale social epidemiological survey for care prevention (12): distinctive findings in socioeconomic status and mental health and tasks for future studies (in Japanese). J Public Health Pract. 2005;69:485-9.

33. Saito Y, Kondo K, Yoshii K, Hirai H, Suemori K, Murata C. The elderly in Japan-a large-scale social epidemiological survey for care prevention (8) Well-being and social support among the elderly-acceptance and provision of support (in Japanese). J Public Health Pract. 2005;69:661-5.

34. Iwasa H. Evaluation scale for social support network among the elderly (in Japanese). Jpn J Geriatr Psychiatry. 2011;22:660-71.

35. Shaw BA, Krause N, Liang J, Bennett J. Tracking changes in social relations throughout late life. J Gerontol Soc Sci. 2007; 62B:S90-9.

36. Yoshii K, Kondo K, Kuze J, Higuchi K. Social relationship factors and risk of care requirement in Japanese elderly (in Japanese). Jpn J Public Health. 2005;52:456-67.

37. Kim H, Sugisawa H, Okabayashi H, Fukaya T, Shibata T. A longitudinal study on social support and life satisfaction among Japanese elderly (in Japanese). Jpn J Public Health. 1999;46: 532-41.

38. Kuroiwa R. Consideration of social policy for the isolated people in community: recent trend in Setagaya (in Japanese). Soc Welf. 2003;44:121-32.

39. Hoshi $T$, Kurimori $S$, Ino $Y$, Takahashi $T$, Hasegawa $T$, Tomoyama G, et al. Relationships between enjoyment and motivation in life regarding outdoor activities and subjective sense of well-being among elderly persons living in urban areas (in Japanese). J Health Welf Stat. 2009;56:16-21.

40. Fujiwara Y, Nishi M, Watanabe N, Lee S, Inoue K, Yoshida H, et al. An intergenerational health promotion program involving older adults in urban areas. "Research of Productivity by Intergenerational Sympathy (REPRINTS)": first-year experience and short-term effects (in Japanese). Jpn J Public Health. 2006;53: 702-14.

41. Kobayashi E. Social relationships in old age. In: Gondo Y, editor. Psychology of aging. Tokyo: Asakura Publishing; 2008. p. 160-1. 